\title{
NONDESTRUCTIVE EVALUATION OF HIGH-TEMPERATURE COATINGS FOR INDUSTRIAL GAS TURBINES
}

\author{
G. L. Burkhardt, G. M. Light, H. L. Bernstein, J. S. Stolte \\ Southwest Research Institute \\ P.O. Drawer 28510 \\ San Antonio, Texas 78228-0510 \\ M. Cybulsky \\ ABB Combustion Engineering \\ 1000 Prospect Hill Road \\ Windsor, Connecticut 06095
}

\begin{abstract}
$\underline{\text { Abstract }}$
Current techniques for determination of the thickness of coatings for gas turbine parts involve metallographic measurements on sections cut from the coated component. This technique is time consuming and expensive, and only a limited amount of data can be obtained for individual systems. In this paper, initial results are presented for a nondestructive technique using eddy current testing. Measurements have bcen carricd out on flat and curved surfaces with and without thermal barrier coatings, and good agreement has been obtained with metallographic determinations in every case. Preliminary data suggest that a combination of eddy current and ultrasonic techniques may enable degradation behavior to be monitored.
\end{abstract}

\section{Introduction}

In order to achieve the high efficiencies demanded of modern combined-cycle generating plants, it is necessary to operate the gas turbine with high turbine entry temperatures. Currently, gas temperatures at the combustor exit are around $1300^{\circ} \mathrm{C}\left(2372^{\circ} \mathrm{F}\right)$, and the objective in turbine development projects such as those in the Advanced Turbine Systems (ATS) program of the U.S. Department of Energy is to devise methods to increase gas temperatures further and to achieve combined-cycle efficiencies of 60 percent. Since the materials used in the hottest parts of the engine are either nickel or cobalt base superalloys with an incipient melting temperature of around $1200^{\circ} \mathrm{C}\left(2200^{\circ} \mathrm{F}\right)$, the use of high gas temperatures requires extensive intcrnal cooling of the blading. The use of ceramic coatings on the component surfaces to provide a thermal barrier offers even more thermal protection. The combined effect of thermal barrier coatings (TBCs) $(1,2)$ and efficient cooling configurations can ensure that metal temperatures remain acceptable with even higher gas temperatures.

A key factor in the effective use of TBCs with advanced cooling configurations is the extent to which the reduction in metal temperature can be used at the design stage to increase the operating capability of the components. Clearly, such a process implies that the integrity of the coating system will be maintained throughout the operating life of the blade or vane. In order to reach this objective, it will be necessary to ensure reliability of the TBC coating system, which consists of an underlying bond coat (usually an overlay coating) and an outer ceramic coating (also called a top coat). This objective implies a consistent and reproducible process for the production of high-quality coatings.

An essential factor in this procedure is the ability to measure coating thickness. Currently, this can only be done by sectioning of coated components and making metallographic measurements of coating thickness. ${ }^{*}$ Clearly, this is a time-consuming operation limited by the cost of providing large parts for destructive examination; and since few data are obtained, statistical evaluation is quite limited. Accordingly, work has been initiated to develop a nondestructive technique to enable thickness measurements to be made on coated parts which will serve as a quality control tool and will enable a large database of information to be obtained. Also, efforts have been made to develop a method for evaluating the degradation of the coating system to determine the condition of the coating in the engine and the remaining coating lifetime. A critical factor is the growth of the oxide between the bond coat and the top coat, which leads to failure of the TBC. Therefore, an ability to monitor $\mathrm{Al}_{2} \mathrm{O}_{3}$ growth rates may provide a basis for determining the onset of failure.

In this paper, techniques being developed are described, and initial results are presented from measurements made with TBCs produced by air plasma spray and with MCrAlY-type bond coats for both flat and curved surfaces.

\section{Experimental Procedure}

\section{NDE Techniques}

In the present program, two techniques are being investigated: the two-frequency cddy current testing (ET) method for determination of coating thickness and ultrasonic testing (UT) and ET techniques for evaluation of coating degradation.

Eddy Current. The ET method involves the generation of a localized electrical current in a conductive material placed in close proximity to a coil energized with an alternating current (3). The ET response is measured as the reactive and resistive components of the electrical impedance of the coil. The ET response is very sensitive to the spacing between the probe and the conductive material, as well as to the conductivity of the material. For specimens with conductive coatings having conductivities that differ from that of the substrate, the response will be sensitive to the conductivity of both coating and base material. The response will also be sensitive to the coating thicknesses and thus can be used for their measurement (3-6). In the case of TBCs, the thickness of the nonconductive ceramic can be readily determined since the response is simply a measure of the spacing between the probe and the layer of bond coat. However, since the thickness and/or conductivity of the bond coat will also affect the ET response, the bond coat thickness can also be measured if the conductivity is constant.

*Alternately, the weight gain of the coated component is used to determine the average coating thickness. However, this method is impractical to determine coating uniformity or in cases where different thickness is required at different locations. 
An example of eddy current data for a coated specimen is shown in Figure 1. Here the data are plotted in the impedance plane with the resistive component of the signal on the horizontal axis and the reactive component on the vertical axis. These data were obtained from an MCrAlY coating similar to those described in this paper The responses are shown for different thicknesses of MCrAlY coating and for different simulated ceramic coating thicknesses. The end points of the traces (A-D) are with zero ceramic thickness, but different MCrAlY layer thicknesses. As the MCrAlY thicknesses increase, the response shifts to the left horizontally. As the ceramic thickness increases, each trace moves from the end point toward the top of the figure. Values of simulated ceramic thicknesses are shown on one trace. From this figure, it is evident that ET is sensitive to thicknesses of both layers.

In order to independently determine the ceramic and bond coat thicknesses, a multiple-frequency method is needed, because additional frequencies (which result in different penetration depths of the eddy currents into the sample) will provide more independent information to help characterize the thickness of each coating layer. Two frequencies were used in the tests to provide four parameters for each measurement. To provide a calibration for measuring the coating thicknesses, a least-squares fit (7) to the ET data was made for data from specimens having different coating thicknesses. Separate fits were made for the bond coat and ceramic layers. The equations from these fits were then used to predict the coating thickness independently for each layer. The equations were of the form:

$$
\begin{aligned}
\mathrm{T} & =\mathrm{C}_{1}+\mathrm{C}_{2} \cdot \mathrm{R}_{1}+\mathrm{C}_{3} \cdot \mathrm{R}_{1}^{2}+\mathrm{C}_{4} \cdot \mathrm{X}_{1}+\mathrm{C}_{5} \cdot \mathrm{X}_{1}{ }^{2} \\
& +\mathrm{C}_{6} \cdot \mathrm{R}_{2}+\mathrm{C}_{7} \cdot \mathrm{R}_{2}^{2}+\mathrm{C}_{8} \cdot \mathrm{X}_{2}+\mathrm{C}_{9} \cdot \mathrm{X}_{2}^{2}
\end{aligned}
$$

where $T$ is the layer thickness, $R_{1}$ and $R_{2}$ are the resistive components and $X_{1}$ and $X_{2}$ the reactive components, respectively, of the two frequencies, and $\mathrm{C}_{1}$, etc. are constants.

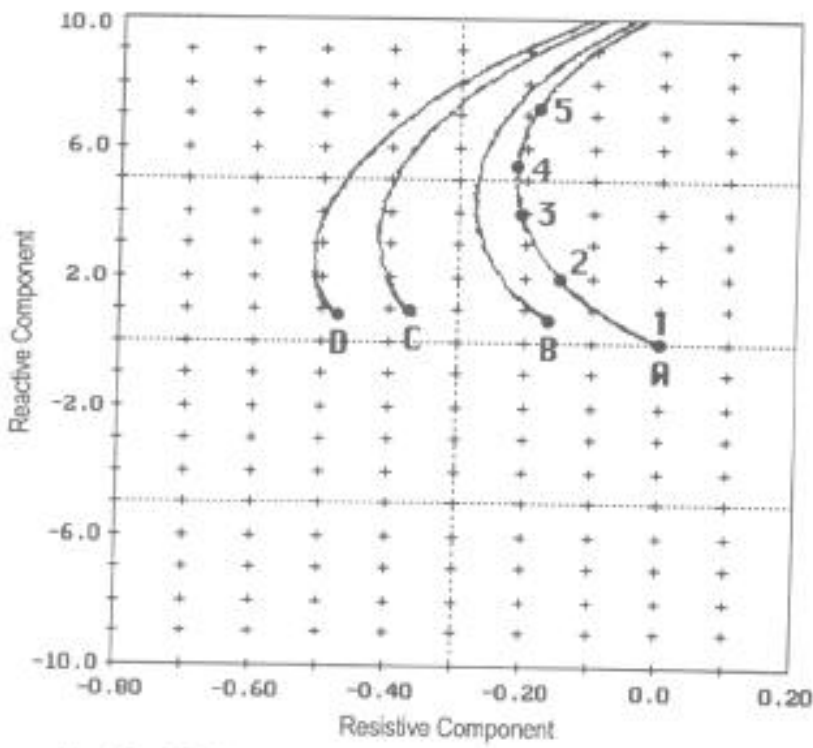

$$
\begin{array}{cc}
\text { Bond Coat Thickness (um) } & \text { Simulated Ceramic Thickness (um) } \\
\hline \text { A - Uncoated } & 1-0 \\
\text { B - } 127 & 2-51 \\
\text { C }-254 & 3-102 \\
\text { D }-381 & 4-152 \\
& 5-254
\end{array}
$$

Figure 1: Example of an impedance plane plot of ET responses to different thicknesses of bond coat and to different simulated ceramic coating thicknesses.
The ET measurements were made using a SmartEddy 3.0 instrument in a portable (lunch-box style) computer with analysis of the data performed offline. The probe was a 0.06 -inch-diameter absolute coil. Excitation frequencies were 1.8 and $4.0 \mathrm{MHz}$. For measurements on flat specimens, the probe was held by a collar, which aligned it with the specimen surface (Figure 2). For measurements on curved blade and vane specimens, the probe was placed in a fixture molded to position it properly against the specimen surface. Repeat measurements made after an interval of time confirmed that good repeatability could be obtained.

Ultrasonics. The ultrasonic method used to investigate degradation involved the application of a pulsed sound wave of high frequency perpendicular to the surface of the specimen (i.e, 0-degree longitudinal wave) and the measurement of the amplitude of the reflected ultrasound from the interface between the ceramic and bond coat.

The UT tests were performed with a Krautkramer USD-15 UT instrument and a $25-\mathrm{MHz}, 6.4-\mathrm{mm}$ ( 0.25 -inch)-diameter focused transducer. The tests were conducted with the probe and specimen immersed in water to provide coupling of the ultrasound to the specimen. (Note that the immersion test was performed for simplicity in the lab; tests could be performed in the field using a gel-type couplant.) The amplitude of the signal reflected from the ceramic/ bond coat interface was measured. Data were taken over the entire specimen surface by performing a raster scan using a laboratory scanner.

\section{Materials}

To establish the feasibility of using nondestructive methods to evaluate TBCs, two types of bond coat were evaluated. The first system was a NiCrAiYSiTa vacuum plasma deposited coating and an air plasma overcoat (coating 1). The second bond coat was a $\mathrm{NiCo}$ CrAIYSiTa deposited by vacuum plasma spraying (coating 2), A third coating (coating 3), similar in composition to coating 1 but with no air plasma overcoat, was used without a TBC to represent the overlay coatings used for blades. In all cases, the substrate was IN-T38LC

To establish the quality of parts such as blades and vanes, it is important to be able to determine the coating thickness on curved airfoil surfaces. The thickness of a coating can vary on an airfoil from less than $100 \mu \mathrm{m}(3.9$ mils $)$ to greater than $325 \mu \mathrm{m}(12.8 \mathrm{mils})$ at the leading edge. In addition to coating thickness, the radius of curvature of the surface changes from relatively flat surfaces on the pressure and suction sides of the airfoil to areas with a high radius of curvature at, for example, the leading and trailing edges.

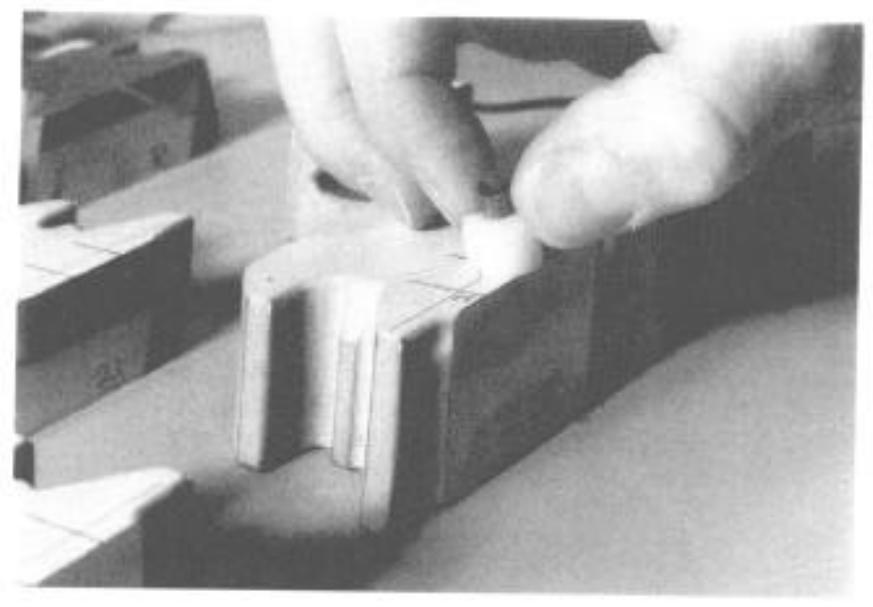

Figure 2: Eddy current probe and holder positioned on a specimen. 
A special fixture was used (Figure 3 ) so that coatings ranging in thickness from $50.8 \mu \mathrm{m}$ ( 2 mils) to over $508 \mu \mathrm{m}$ ( 20 mils) could be applied on the surface of stage 1 blade and vane sections for a large gas turbine engine. Coated areas of various thicknesses were produced by removing sections of the fixture in turn and spraying the exposed surface while the rest of the surface was masked. After coating, the airfoil sections were heat treated and sectioned across the chord width into pieces approximately $9.5 \mathrm{~mm}(0.375$ inch) wide. These sections were ground and polished, and the coating thicknesses were determined at various locations on the airfoil.

In order to simulate a degraded coating, static oxidation tests were performed on specimens with coating 2 at $1150^{\circ} \mathrm{C}\left(2100^{\circ} \mathrm{F}\right)$ for 15 hours and 75 hours. Figure 4 shows the typical layers which can form on an oxidized TBC coating.

\section{Results}

\section{Flat Surface Thickness Tests}

The ET results for coating 1 with a flat surface are shown in Figures 5 and 6 for the ceramic and bond coat layers, respectively, The fits to the ET data are plotted as a function of thickness measurements obtained from metallographic examination of coated sections. The results in both figures represent different fits to the same data, which were taken from specimens having varying thicknesses for both layers. The ceramic thickness measurements in Figure 5 were thus made in the presence of varying bond coat thickness and include the effects of this varying thickness on the accuracy of the ceramic measurement. Likewise, the results in Figure 6 include the effects of varying ceramic thickness on the bond coat thickness measurement.

The agreement between the ET and metallurgical results for the ceramic thickness (Figure 5) are very good, with an rms error (RMSE) of 13.3. The results for the bond coat have more scatter, with an RMSE of 17.6. A contributor to this variability is believed to be the effect of the coarse powder used for the air plasma sprayed top
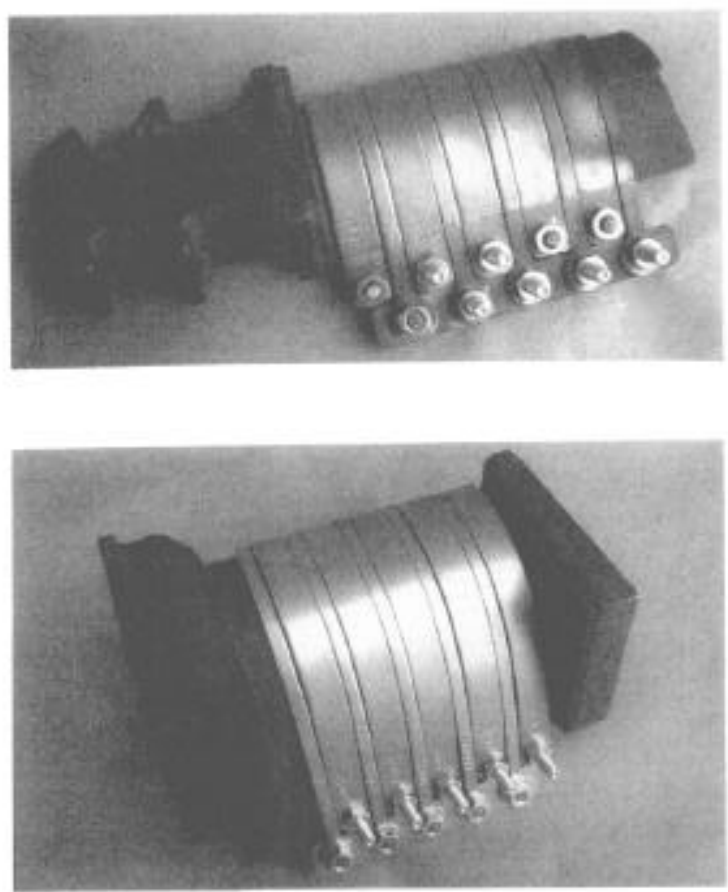

Figure 3: Fixturing for coating gas turbine blades above and vanes below.

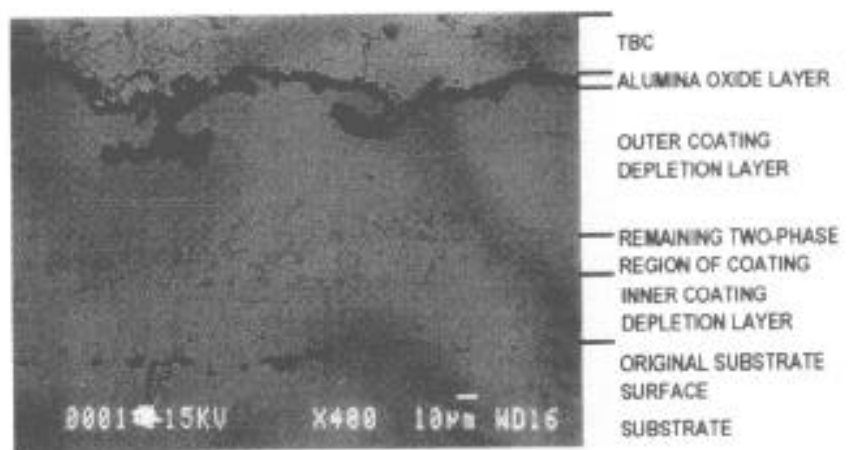

Figure 4: Cross section of coating 2 flat panels oxidized at $1150^{\circ} \mathrm{C}$ (2) $\left.100^{\circ} \mathrm{F}\right) / 50$ hours. Note coating degradation, i.e., coating depletion layer and growth of oxide.

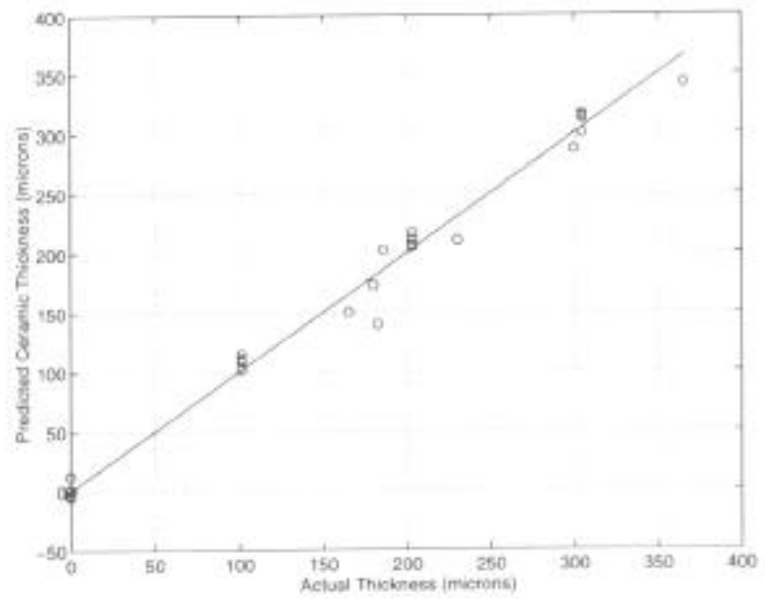

Figure 5: Eddy current thickness measurement of ceramic layer fot flat samples with bond coat 1 . Solid line represents ideal $1: 1$ relationship between actual and calculated values.

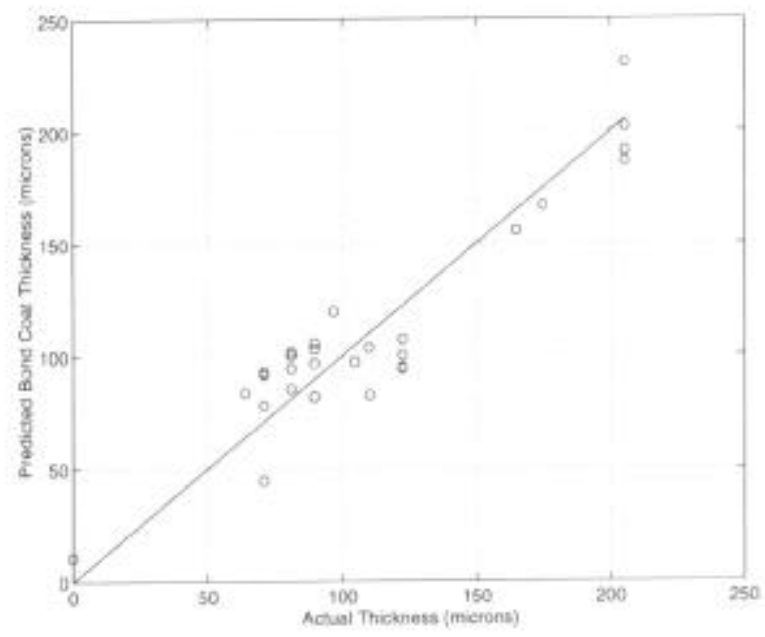

Figure 6: Eddy current thickness measurement of bond coat layer for flat samples with bond coat 1 . 
layer of this coating. It is believed that the result is localized variations in the conductivity of the coating which affect the ET response and reduce the accuracy of the thickness measurement.

Similar data are presented for coating 2 in Figures 7 and 8. The fit for the ceramic thickness (Figure 7) is very good (RMSE $=11.4$ ) and is comparable to that for the ceramic layer with coating 1 (Figure 5). The results for the bond coat (Figure 8), however, are much better than for coating 1 (Figure 6), with an RMSE of 7.5. This result is attributed to the finer powder used in the final stages of the spray process for coating 2 .

\section{Curved Surface Thickness Tests}

Next, the ability to measure coating thicknesses on actual components with curvature was investigated for a blade and a vane. Measurements were made at the locations shown in Figure 9. Data will be shown for location $\mathrm{C}-2$ on the vane and on the blade. The results at these locations are typical of most other locations. An exception is the leading edge, for which the data analysis has not been finalized.

Results from the vane coated with bond coat 1 are shown in Figures 10 and 11 for the ceramic and bond coat layers respectively. The agreement between the ET results and the metallurgical results are good for the ceramic coat $(\mathrm{RMSE}=16.0)$, but show more scatter for the bond coat (RMSE $=30.6$ ). Some of the scatter may be caused by the coarse powder used in the air plasma overcoat, as was the case for the flat specimens with coating 1 (Figure 6). The fact that the scatter is larger for the vane is also attributed to the fact that the ET data were fit to a larger range of thicknesses, which could reduce the fit accuracy.

The results obtained from the blade coated with bond coat 3 are shown in Figure 12 for the bond coat layer. Agreement with the metallographic measurements is good (RMSE $=12.0$ ). The error is larger than obtained with coating 2 (Figure 8 ), which may he a result of fitting the ET data to a larger range of thicknesses. Since the variability in the ET results is still reduced compared to the air plasma layer case (Figures 6 and 11), this provides further evidence that the additional variability observed in Figures 6 and 11 was caused by the coarse powder used for the top layer applied by air plasma spray.

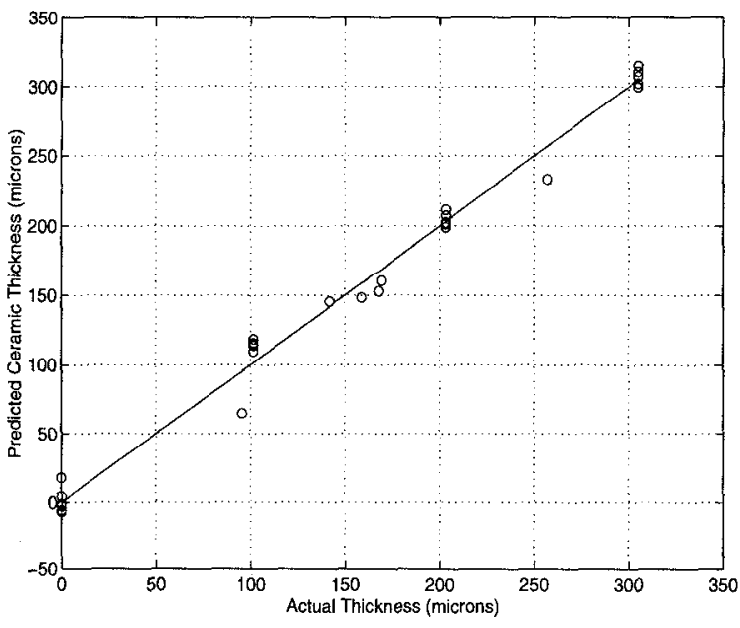

Figure 7: Eddy current thickness measurement of ceramic layer for flat samples with bond coat 2 .

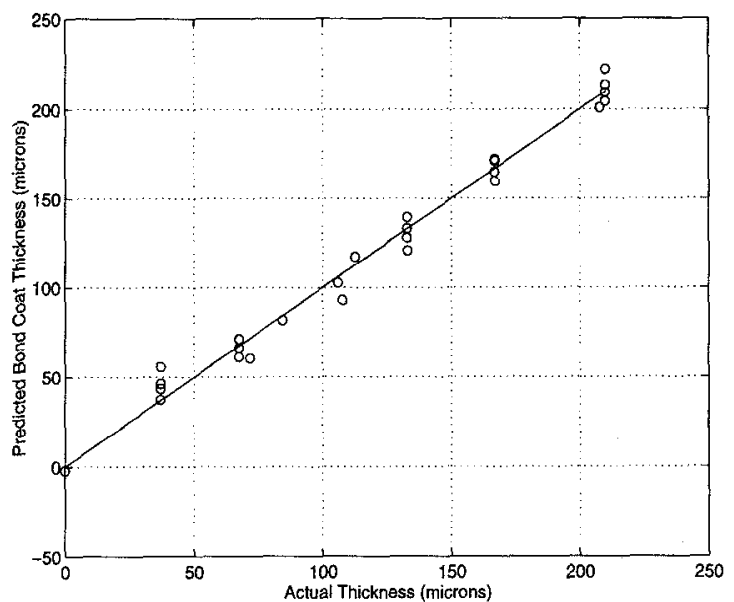

Figure 8: Eddy current bond coat thickness measurement for flat samples with bond coat 2 .
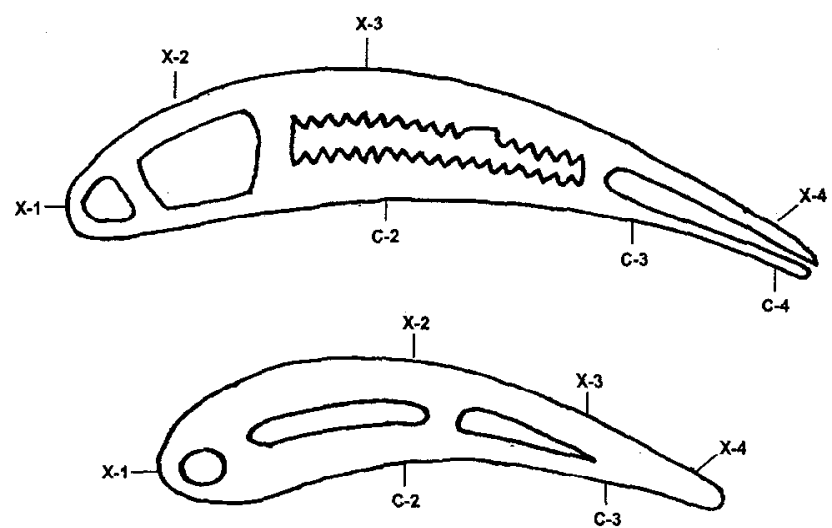

Figure 9: Coating thickness measurement locations for stage 1 vane above and stage 1 blade below.

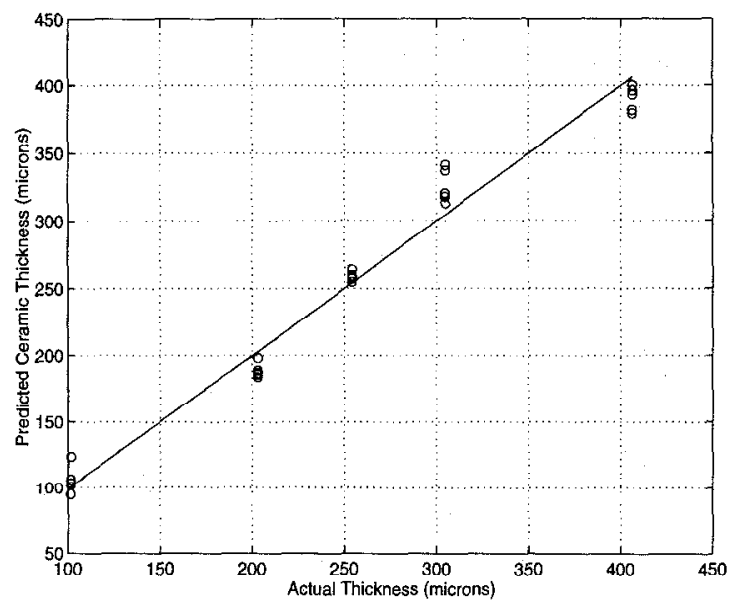

Figure 10: Eddy current ceramic coating thickness measurement at position C-2 for vane with bond coat 1 . 


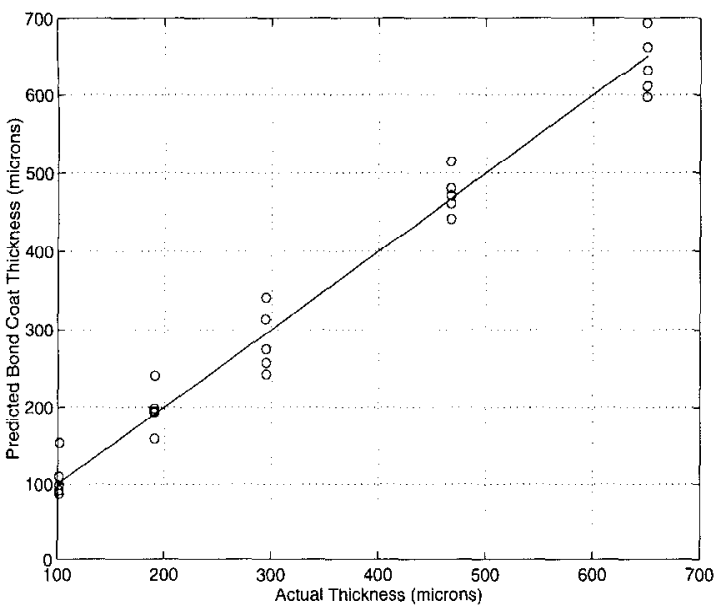

Figure 11: Eddy current bond coat thickness measurement at position C-2 for vane with bond coat 1 .

\section{Degradation Studies}

The UT response after exposure of the samples to an oxidizing environment at high temperature showed that the amplitude of the signal reflected from the interface between the ceramic and the bond coat increased with time of exposure. Thus, the signal increased by 5 and $7.5 \mathrm{~dB}$ for exposure times [at $1100^{\circ} \mathrm{C}\left(2100^{\circ} \mathrm{F}\right)$ ] of 15 and 75 hours, respectively (Figure 13). The signals shown in the figure are taken from a single location on each specimen, but are typical of the signals observed in scans over the entire specimen surface. The cause of the signals is believed to be an increase in the acoustic impedance mismatch at the ceramic/bond coat interface due to the growth of an alumina layer.

The ET signal also responds to the degradation associated with this exposure. Figure 14 shows the impedance plane display of ET signals from the degraded specimens. The endpoints of the signals represented by dots are with the probe on the specimen surface, and the vertical lines are generated as the probe is lifted off of the surface. The separation between the endpoints (dots) shows a definite

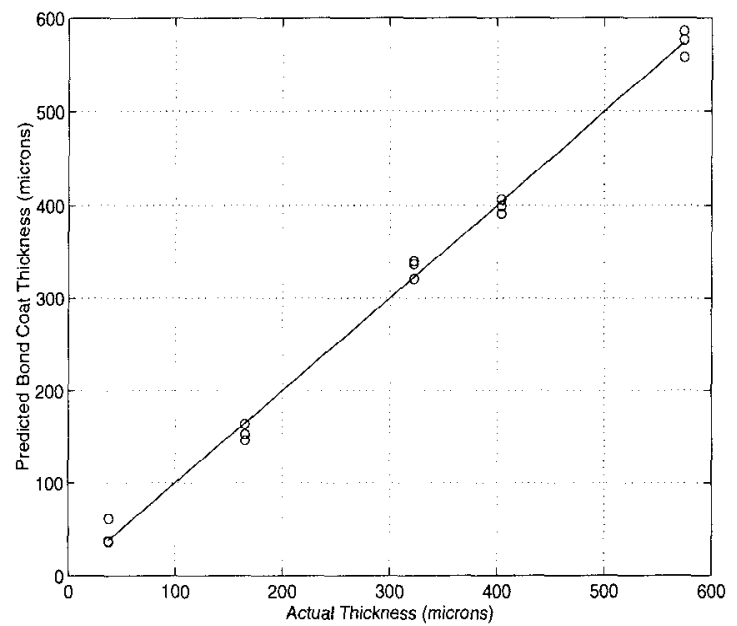

Figure 12: Eddy current bond coat thickness measurement at position C-2 for blade with bond coat 3 .

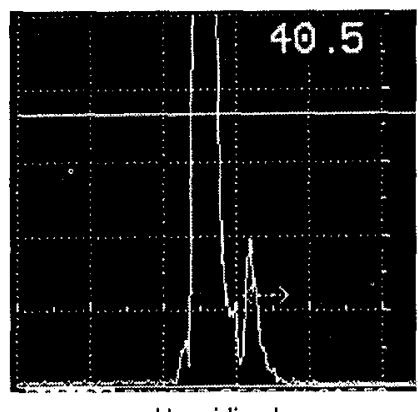

Unoxidized

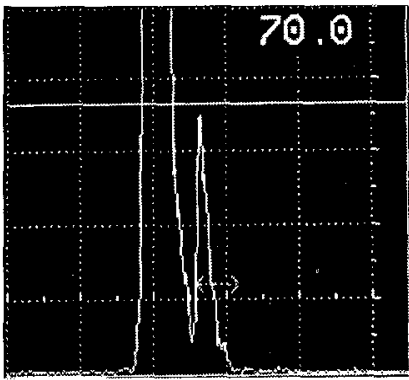

Oxidized for 15 Hours

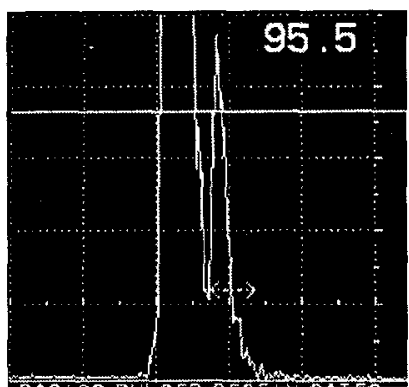

Oxidized for 75 Hours

Figure 13: Ultrasonic A-scan of a thermal barrier coating system oxidized at $1100^{\circ} \mathrm{C}\left(2100^{\circ} \mathrm{F}\right)$. Note that the second signal (two divisions amplitude in the unoxidized case) is from the thermally grown oxide on the bond coat. The signal height increases by 5 and $7 \mathrm{~dB}$ for 15 - and 75-hour samples, respectively, over the signal from the unoxidized sample.

change with degradation. While the precise reason for the response is as yet unclear, factors such as changes in conductivity due to second-phase particles in the bond coat and formation of a depleted layer at the interface between bond coat and TBC may have an influence.

\section{Discussion}

Two-frequency ET results show that very good relationships are obtained between the ET data and actual coating thickness for both the bond coat and ceramic coatings. The bond coat thickness can be measured independently of varying ceramic thickness, and the ceramic thickness can be measured independently of varying bond coat thickness. This was demonstrated for two different bond coat systems, and for flat specimens, as well as for actual vanes and blades with curved surfaces. In most cases, the ET results agreed with actual metallurgical sectioning results within approximately $\pm 15 \mu \mathrm{m}(0.6 \mathrm{mil})$ for the ceramic layer and $\pm 16 \mu \mathrm{m}(0.6 \mathrm{mil})$ to $\pm 40 \mu \mathrm{m}$ (1.6 mils) for the bond coat layer. The higher variability in the bond coat layer was experienced where a coarse powder was used for the top layer of the bond coat. 


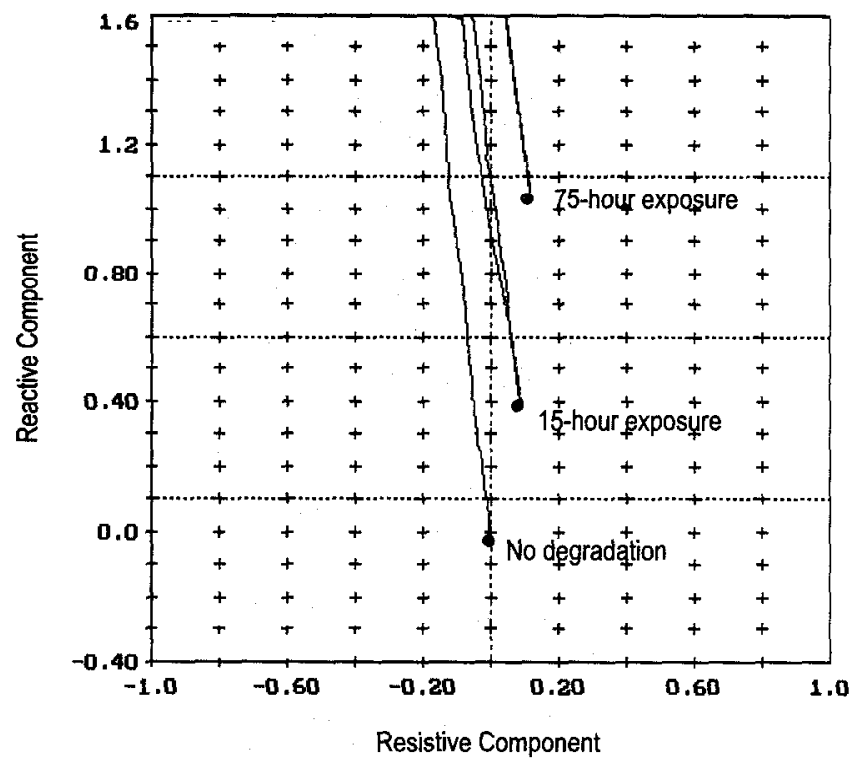

Figure 14: Impedance plane plot of ET responses to specimens with bond coat 2 and no degradation, 15-hour exposure, and 75 hour exposure. The vertical signal component is from probe liftoff.

The next step toward demonstrating a thickness-measurement technique for practical application is to investigate the variability in the coating process on the ET response. This would be done by using the relationships between ET data and thickness (described in this paper) as a calibration and performing blind tests on specimens which have been coated at different times and with different setups. Good results from these tests would indicate a robust measurement approach capable of field application.

Results from limited tests with degraded spccimens subjected to high-temperature exposure show that UT appears to be sensitive to the growth in the alumina layer between the bond coat and ceramic. In addition, the ET response is affected by changes in electrical conductivity associated with degradation process and/or the formation of a depleted layer at the bond coat/TBC interface. Although these results are very preliminary and are based on limited data, they indicate promise for use of these techniques to sense degradation. Additional work needs to be performed to more precisely relate the responses of these techniques to the degradation process.

\section{Conclusions}

1. The application of the dual-frequency eddy current technique for the measurement of the thickness of as-sprayed overlay and ceramic coatings has been successfully demonstrated on flat surfaces and airfoils. The method provides a basis for a nondestructive tool for quality assessment of coatings on turbine parts.

2. The correlation between eddy current and metallographic measurements was better on TBC bond coats without an air plasma sprayed layer, presumably a result of electrical conductivity variations caused by the coarse structure of this layer.

3. Preliminary work shows that both ultrasonic and eddy current techniques may yield information on coating degradation.

\section{Acknowledgment}

Dr. T. B. Gibbons, ABB-CE, has made helpful comments on the text.

\section{References}

1. H. L. Bernstein and J. M. Allen, "A Review of High Temperature Coatings for Combustion Turbine Blades," Proceedings of the Steam and Combustion Turbine-Blading Conference and Workshop-1992, TR-102061, Research Project 1856-09, April 1993, 6-19-6-47.

2. C. H. Liebert and R. A. Miller, "Ceramic Thermal Barrier Coatings," Ind. Eng. Chem. Prod. Res. Dev. 23 (1984) 344-349.

3. H. L. Libby, Introduction to Electromagnetic Nondestructive Test Methods, (New York, NY: Wiley-Interscience, 1971) 46.

4. D. J. Hagemaier, "Applications of Eddy Current Testing to Airframes," Nondestructive Testing Handbook, Volume 4: Electromagnetic Testing (Columbus, OH: American Society for Nondestructive Testing, 1986) 369.

5. J. C. Moulder, E. Uzal, and J. H. Rose, "Thickness and Conductivity of Metallic Layers from Eddy Current Measurements," Rev. Sci. Instrum. 63 (1992), 3455-3465.

6. J. K. Hulbert and B. W. Maxfield, "Thin, Finite-Plate, Clad Thickness Determination Using Eddy Currents," Review of Progress in Quantitative Nondestructive Evaluation, Volume 7A, ed. D. O. Thompson and D. E. Chimenti (New York, NY: Plenum Press, 1988), 199-206.

7. W. E. Deeds, C. V. Dodd, and G. W. Scott, "Computer-Aided Design of Multifrequency Eddy-Current Tests for Layered Conductors with Multiple Property Variations," ORNL/TM-6858, Contract No. W-7405-eng-26, Oak Ridge National Laboratory, October 1979 . 